\title{
Big Data and the Future of the Accounting Profession
}

\author{
Nagat Mohamed Marie Younis* \\ College of Business, Department of Accounting, University of Jeddah, Saudi Arabia
}

\begin{abstract}
Article Type: Article
Article Citation: Nagat Mohamed Marie Younis. Big data and the future of the accounting profession. Indian Journal of Science and Technology. 2020; 13(08),883-892.D0l:10.17485/ijst/2020/ v013i08/149808
\end{abstract}

Received date: December 30, 2019

Accepted date: February 4, 2020

*Author for correspondence: Nagat Mohamed Marie Younis nmarie@uj.edu.sa 9 College of Business, Department of Accounting, University of Jeddah, Saudi Arabia

\begin{abstract}
Background/objectives: The purpose of this research is to study and analyze the Big Data, to identify the challenges which facing Big Data in business organizations, and to clarify the impact of Big Data on changing the roles of accountants and accounting profession. Determining the impact of big data analysis on improvement accounting information quality. Methods/statistical analysis: To achieve this objective, reference was made to previous studies and related research, with a qualitative study based on in-depth and semi-structured interviews with specialists in the field of accounting and data analysis. Findings: The study concluded the impact of big data on the roles of accountants and the profession of accounting in the future, the importance of big data analysis in improving the accounting information quality. Improvements/applications: The other main findings of this research are that the importance to teach Big Data and business analysis in the curriculum of accounting education at the university level to enhance students' knowledge on the importance of such data and how to process, store, and use them in the accounting field. The study recommends carrying out further scientific and applied research in Big Data to know its impact on the developments of the accounting profession. Originality/ value: The original contribution of the study lies in the empirical investigation of the phenomenon of Big Data and the extent of the need for it because it provides great opportunities in the field of accounting measurement, changing the roles of accountants, the development of the accounting profession, and improving the quality of accounting information as one of the most recent developments in the accounting context.
\end{abstract}

Keywords: Big Data, Big Data Analysis, Accountants, Accounting Profession, The Accounting Information Quality.

\section{Introduction}

We live in a huge amount of Big Data, these Data become a store for value when they converted to information, With the increasing volume of Data, companies found two 
ways, either ignore these Data or processed and used in achieving competitive advantage, improving accounting information, raising the efficiency of capital markets, and assisting officials and investors to make correct decisions [1]. The topic of Big Data and its importance to the accounting profession is an important subject that needs further discussion and analysis.

Big Data is one of the most pressing challenges in the accounting profession, where the accounting profession faces many challenges such as rapid financial and economic changes, financial corruption, globalization, lack of knowledge of new developments in information technology, and other challenges. Therefore, it is necessary to start quickly the needed plans to overcome these obstacles and work to make the ambitions of the accounting profession, through a distinguished place for the professionals and Accountants and the use of the high potential of information technology.

Accounting information quality is an important issue in recent times due to the financial crises by business organizations and which negatively affected the users of financial reports, and information has a major role in the decision-making and the strategic plans and policies of the organization. Although the abundance of data of this age, it also challenges the accountants and decision-makers. Where big data is one of the challenges faced by companies because of the difficulty of processing and utilization. Therefore, the subject of analyzing big data and its importance to the accounting profession is an important subject and needs further discussion and analysis, and the article tries to answer the following questions:

(1) Does big data affect the roles of accountants and the profession of accounting in the future?

(2) Does the analysis of big data affect the quality of accounting information?

\section{Theoretical Framework of Big Data}

\subsection{The Concept of Big Data, Types, and Characteristics}

The concept of "Big Data" found the interest of many researchers in accounting thought, Wikipedia has defined it as "it is a collection of Data sets so large and complex that it becomes difficult to process using on-hand Database management tools or traditional Data processing application", as Gartner Inc. defined it as "the term high Data is highvolume, high-velocity and/or high-diversity information assets that demand cost-effective, innovative forms of information processing that enable enhanced insight, decision making, and process automation" [2], and it is recognized by the International Organization for Standardization as "a set or sets of Data with unique characteristics such as size, speed, diversity, variable, reliability and Data health that cannot be efficiently addressed using traditional technology to benefit from it" [3]. Big Data can be divided into Structured Data, Unstructured Data, and Semi-structured Data [4]. Big Data can be described by the following characteristics: Volume, Velocity, Variety, Veracity, Value, variability, and visualization [5-6].

Big data analysis was defined as the process of collecting, organizing and analyzing large data to discover, visualize, display of patterns, knowledge, intelligence, and other 
information within big data [7]. The study [8] shows that organizations use analytical tools in the field of marketing, communications, retail, and audit to discover the potential opportunities in big data, there are many tools and techniques used to analyze such data: Hadoop, MapReduce, NoSQL, Grid Gain, HPCC, Storm, Sap Hana, and Cassandra.

\subsection{The Importance of Big Data}

Studies [7-14] have shown the importance of Big Data analysis as follows: Provides a highly competitive advantage for enterprises, rationalize decision-making, Contribute to give a comprehensive overview of the company, and develop a business strategy, Supports integrated reporting more effectively, using both financial and non-financial information to disclose the company's performance, Helps to improve risk management, and discover opportunities to reduce costs. Big Data analytics helps companies better understand customer behavior to increase customer satisfaction, increase business efficiency, increase sales, and increase opportunities for innovation in process and product development. Big Data represents the future and evolving aspect of the information industry and value creation to the aim of developing the economy, promoting growth, increasing productivity and quality of products [15], and that the analysis of Big Data helps to increase the knowledge content of financial information, especially when allocating the securities portfolio [16].

\subsection{Challenges of Big Data}

There are many challenges faced by organizations when dealing with Big Data such as the phenomenal growth in the amount of Data, random search and retrieval within those Data, Data diversity, Data security, the lack of specialists in the analysis of Big Data, lack of expert automated systems that suit the needs of the organization and have good capabilities in the use and development [17-20]. The study [21] illustrates the challenges faced by organizations in the use and analysis of Big Data, The challenges divided into three sections: First: Data-related challenges: Volume, Variety, Velocity, Veracity, Data quality, Data discovery, relevance, inclusiveness, privacy; Second: process-related challenges include Data households, the difficulty of choosing between similar Data, transforming Data into a form of analysis, Data modeling, understanding of outputs, how to present complex analyses of Data; and Third: Management challenges include Data privacy, security, governance, and ethics [22].

\subsection{The Impact of Big Data on the Future of Accountants}

Big Data affect the roles of accountants in the coming years. As it provides an opportunity for accountants to move into strategic roles in organizations [23], and that their role in decision-making changes to business partners. At present, the technology employs many of the functions of accountants, but in the future, the accountant will be an important link between Data analyst and senior management, the supervisor on privacy and ethical use of Data by having the skills of managing and analysis of Big Data. The study [24] noted 
that there is a risk to the accounting profession in the era of Big Data, as about $94 \%$ of the accounting and auditing functions will become automatic, but accountants can create value by acquiring Big Data analysis skills, as they are distinct in understanding and analyzing Data structured in the financial statements to assess the company's performance, thus facilitating the transition to working with unstructured Data by possessing skills of Big Data analysis, so instead of replacing accountants. Therefore, universities and professional organizations must train new students from accountants to analyze Big Data, learn new techniques that keep them in contact with Data scientists, and standards makers must change curricula and standards to accommodate the challenges of Big Data analyzes.

Analyzing the role of accountants in the age of Big Data, the study [25] explained that accountants have a little understanding of the steps necessary to transform Big Data into useful information, there is high in demand for analysts to conduct Big Data analysis [26]. Therefore, accountants must aware the importance of Big Data through increasing their ability and skills to interpret and analyze Big Data to add value to business organizations, and that this limited understanding by accountants creates a gap between what accountants can do and what they should do. So, the study presented a model for the life cycle of Big Data to explain the process of converting Big Data to useful information, while highlighting the risks of control and information, The study found that this model represents the first attempt to recognize that accountants need to develop the accounting profession and they have an important role in the governance of Big Data, and the ability to determine the information for decision-makers.

Big Data affect the future of companies and change of roles of financial accountants, as it provides an opportunity for accountants to take a more strategic role in the future, through training in the collection and analysis of financial information and apply their basic skills on non-financial information. In [27] the era of Big Data, the role of accountants will increase in the future because the analysis of Big Data has a high explanatory capacity to illustrate corporate reports [28]. The study [29] emphasized that accounting and finance professionals need to close the gap between the IT department and business, as they are not software engineers or Data scientists. He pointed out that candidates for new positions of accountants who have technical skills and statistical skills to manage and analyze Big Data and they will receive the highest salaries in business organizations.

The study [30] shows that accountants must aware of the changes created by Big Data such as cloud computing, social media, cybercrime, digital services, and artificial intelligence. The next changes represent an opportunity to redefine roles and to what extent they will participate in decision-making, AAA encouraged the integration of Big Data education. The Journal of Accounting Education called for the inclusion of papers on Big Data in its special edition in March 2017 to encourage the study of Big Data, its analysis and time series analysis in the curriculum.

Accounting programs should include learning experiences that develop skills and knowledge related to the integration of information technology into accounting and business. These learning experiences include developing skills and knowledge related to Data creation, Data management, and participation, Data analysis, Data modification, Data reporting, Data security, Data analysis, business analysis, IT skills, and knowledge development are essential components of accounting approaches [31]. 


\subsection{The Impact of Big Data on the Future of the Accounting Profession}

Big Data does not affect the primary aim of accounting, which provides useful information to internal and external decision makers, but Big Data affect the accounting profession [32], where there is an increase in the financial Data represented by video Data, images, audio, text, and e-mail, so accountants must sufficiently aware of the impact of Big Data on traditional accounting records and information, the study [33] pointed out that Big Data includes the following:

\subsection{Video and Image Data}

Visual Data has become more widespread and the use of this Data has become a reality to increase accounting records, such as image and video storage, and include workplace video to track worker productivity, video of inventory to check real-time changes to measure productivity and find bottlenecks, and a video of property status, buildings, and equipment as an extra element to discuss possible impairment issues, video of interviews conducted in the company can also be a source of accounting information, so management interviews are periodically analyzed to extract content, emotion, and deception to provide non-verbal information about business risk and audit.

\subsection{Audio Data}

Audio Data related to the Company's activities work enhance of accounting records and improve financial information quality, Audio sources include quarterly conference calls, shareholder and board meetings, customer calls, and internal phone calls for staff, and Audio Data analysis achieves annual quarter earnings, knowledge of customer satisfaction and product quality. Big Data provides more evidence to support accounting records; Audio interviews with construction engineers during the asset-building phase give more evidence of value, benefit assessment, security and control of the asset, and employee productivity. This will help accountants in the future to understand the basis for long-term asset valuation and address asset impairment issues.

\subsection{Textual Data}

Textual Data represents non-financial documents, such as e-mail messages and web pages, including corporate documents on company sites, social media such as Facebook and Twitter users. Data from these sources will be useful in marketing, giving early warning to customer service about product defects, forecasting sales volume, measuring satisfaction levels, and evaluating and improving business performance. Companies extract and merge Big Data formats with traditional financial Data to enhance their ability to assess and predict business performance, improve transparency, and rationalize decision-making. From the above, the forms of Big Data discussed in this article (i.e., video, images, audio, and text) complement traditional financial information and can improve transparency and usefulness for decision-making. 
Big Data affects financial accounting by influencing how Data is collected and recorded, Data management, preparation of financial statements, financial accounting is an information system for recording, storing, retrieving, summarizing, analyzing and presenting transactions and financial and economic events. It is expected that Big Data will be linked in financial accounting, by integrating different Data sources into accounting information systems. For example, text, video, images, and audio Data are gradually linked to traditional Data, this requires from accountants to improve their skills when use and analyzing Big Data. So, Accounting information systems with Big Data analyzes can be a driving force for successful organization management. Big Data may affect fair value accounting so that Big Data relating to the fair value of assets and liabilities can reduce subjective assumptions in fair value estimates [34]. The study [35] noted the importance of Big Data in accounting and auditing, where Big Data techniques used in models of financial failure forecasting, stock market forecasting, and quantitative modeling. The study [32] indicated the importance of Big Data and its implications for the accounting profession, where image, video, audio, and text Data improve management accounting, financial accounting, and practices of financial disclosure. In management accounting, Big Data will contribute to the development of management control systems and the efficiency of budget preparation processes. In financial accounting, Big Data will improve the quality and relevance of accounting information, thereby enhancing transparency and rationalizing decision-making for stakeholders. In financial disclosure, Big Data create and improve accounting standards, helping to ensure that the accounting profession continues to provide accurate and useful information in the dynamic global economy evolves.

\section{Research Methodology}

The study aims to identify the attitudes and opinions of academics, financial analysts, accountants, and experts in big data analysis (BDA) on determining the impact of big data analysis on the future of the accounting profession and improving the quality of accounting information in the Saudi environment.

The present study is a qualitative study based on in-depth and semi-structured interviews with specialists in the field of accounting and data analysis. The analysis of the interview data was conducted by (154) participants to provide an insight into the future of the accounting profession in the era of big data, and Quality of accounting information.

The data was collected during two sessions. The first data collection session was held in July 2018, which included semi-structured interviews with the first (63) participants. Then began the second round of data collection in November 2018 with the remaining (91) participants and ended in early January 2019, this second session of data collection helped to expand, develop, and validate the results developed as part of the first session.

Table 1 presents the distribution of the sample of the study according to the years of experience, and the extent of the need for big data analysis. The number of (51) from the total participants of the study has been practicing the profession for 10 years or more by $33.1 \%$, (59) has experience for the period between 5 and 10 years by $38.3 \%$, and (44) has 
TABLE 1. Characteristics of the participants

\begin{tabular}{llllllll}
\hline Participants & \multicolumn{3}{c}{ Years of experience } & \multicolumn{2}{c}{ The need for Big Data analyze } \\
\cline { 3 - 8 } & & $\begin{array}{c}\text { 10 years } \\
\text { and over }\end{array}$ & $\begin{array}{c}\mathbf{5 - 1 0} \\
\text { years }\end{array}$ & $\begin{array}{c}\mathbf{5} \text { years } \\
\text { and less }\end{array}$ & $\begin{array}{c}\text { Continuously } \\
\text { Arregular }\end{array}$ & Very rare \\
\hline \multirow{2}{*}{ Academics } & No. & 13 & 20 & 9 & 22 & 16 & 4 \\
& $\%$ & 31 & 47.6 & 21.4 & 52.4 & 38.1 & 9.5 \\
Financial & No. & 15 & 12 & 8 & 15 & 11 & 9 \\
analysts & $\%$ & 42.9 & 34.3 & 22.9 & 42.9 & 31.4 & 25.7 \\
Accountants & No. & 17 & 12 & 8 & 7 & 11 & 19 \\
\multirow{4}{*}{ Experts in } & $\%$ & 45.9 & 32.4 & 21.6 & 18.9 & 29.7 & 51.4 \\
BDA & No. & 6 & 15 & 19 & 26 & 12 & 2 \\
Total & $\%$ & 15 & 37.5 & 47.5 & 65 & 30 & 5 \\
& No. & $\mathbf{5 1}$ & $\mathbf{5 9}$ & $\mathbf{4 4}$ & $\mathbf{7 0}$ & $\mathbf{5 0}$ & $\mathbf{3 4}$ \\
& \% & $\mathbf{3 3 . 1}$ & $\mathbf{3 8 . 3}$ & $\mathbf{2 8 . 6}$ & $\mathbf{4 5 . 5}$ & $\mathbf{3 2 . 5}$ & $\mathbf{2 2}$ \\
\hline
\end{tabular}

experienced less than 5 years by $28.6 \%$. In terms of the need for analysis of big data, it was found that (70) of the total sample needed continuously information at $45.5 \%$ because it provides great opportunities in the field of accounting measurement, changing the roles of accountants, the development of the accounting profession in the future, (50) need this information irregularly by $32.5 \%$, the number (34) need this information very rarely by $22 \%$.

\section{Results}

Our qualitative study based on in-depth interviews with accounting academics and professionals lead the following findings:

- There is an impact on the roles of accountants and the accounting profession in the future. Big data will change the role of the accountants, affects accounting and accounting measurement by collecting and recording data, managing data, and preparing and reviewing financial statements. Big data of images and video affects traditional accounting records and provides additional evidence to support those records.

- The accountants must develop skills and knowledge regarding data creation, management, modification, storage, analysis, reporting, and security. They must be familiar with the changes made by big data, such as cloud computing, social media, cybercrime, digital services, and artificial intelligence. So, Accountants with technical and statistical skills to manage and analyze big data will receive the highest salaries in economic units.

- Big data analysis provides relevant, valuable information that helps stakeholders to make decisions, which leads to the improvement of the quality of accounting information and thus reduce information asymmetry.

- Big data analysis of discussions, Audio, and videos improves the understanding of the content of accounting information and annual financial reports by providing detailed economic unit data, thus increasing the credibility and quality of accounting information. 
- Big data analysis improves the understanding of the nature of different processes in the economic unit and improves understanding of the strategic performance of the economic unit as a whole and improves future growth opportunities and the predictability of future profits and risks, increasing the credibility and accounting information quality.

\section{Conclusions and Recommendations}

In this study, we focused on the Theoretical Framework of Big Data (concept, types, characteristics, importance, challenges), Big Data will develop accountants and accounting profession in the future, a successful accountant needs analytical skills and information management to transform Big Data into added value, with accountants' knowledge of the opportunities and risks associated with Big Data, business organizations achieve many advantages when analyzing of Big Data, including increasing the understanding of the company's activities, developing its strategy and business model, achieving high competitive advantage, improving accounting information quality, providing appropriate information to help rationalize decision-making, as well as a source of future information that influences stakeholder decisions. There are challenges faced by organizations in the analysis of Big Data, the most important of the lack of specialized staff in the analysis of Big Data, the high costs of employing experienced professionals, the rapid flow of Big Data, the difficulty of transferring, storing, processing of Big Data, and the difficulty of understanding and clarity when presenting Big Data analyzes.

The study concluded the impact of big data on the roles of accountants and the profession of accounting in the future, the importance of big data analysis in improving the accounting information quality.

Furthermore, there is a need to teach Big Data and business analysis in the curriculum of accounting education at the university level, the need to adopt the AACSB standard 7 entitled "Information Technology Skills and Knowledge for Accounting Graduates", and the introduction of a new standard for Big Data. Establish workshops and training courses for researchers and academics and introduce them to the importance of Big Data analysis and how to process, store, manage and use them in the financial accounting. This research is an open invitation to further scientific and applied research in Big Data and its impact on the developments of the accounting profession.

\section{References}

1. Al-Akbali A. Transforming Big Data into value added. King Fahad National Library Journal. 2017, 23(2), 1-24. https://kfnl.gov.sa/Ar/mediacenter/EMagazine/DocLib/23_2/82_102.pdf

2. Big Data. https://www.gartner.com/glossary/Big-Data. Date accessed: 18/03/2018.

3. Big Data. http://www.iso.org. Date accessed: 14/10/2017.

4. Rashwan, A. The role of analysis of Big Data in the rationalization of financial and administrative decisions in the Palestinian universities - a field study. Journal of Economic and Financial Studies. Faculty of Economic and Commercial Sciences and Management Sciences. Algeria. 2018, 11 (1), 22-41. https://www.asjp.cerist.dz/en/article/61350 
5. Al-Salmi G. Big Data and its role in supporting decision-making and strategic planning. In: 24th annual conference of the association of specialized libraries. Gulf Arab Branch. Muscat. 6-8 March 2018; 1-8. https://www.researchgate.net/publication/334194323

6. O'Leary, D. Big Data and knowledge management with applications in accounting and auditing: the case of Watson. 2018; 1-24. https://ssrn.com/abstract=3203842

7. Sun Z, Sun L, Strang K. Big Data analytics services for enhancing business intelligence. Journal of Computer Information Systems. 2018, 58 (2), 162-169. https://www.researchgate.net/ publication/309389413

8. Salijeni, George M. Big Data analytics and the social relevance of auditing: an exploratory study. A thesis submitted to the University of Manchester for the degree of Doctor of Philosophy. The Faculty of Humanities. Alliance Manchester Business School. 2019; 1-262. https://www. research.manchester.ac.uk/portal/files/95492166/FULL_TEXT.PDF

9. Salijeni G, Samsonova A, Turley S. Big Data and changes in audit technology: contemplating a research agenda. Accounting and Business Research. 2019, 49(1), 1-26. https://www.tandfonline. com/doi/abs/10.1080/00014788.2018.1459458

10. Al-Sheikh R. The age of Big Data, how did the world benefit from it. https://www.alarabiya.net/ en/qafilah. Date accessed 19/11/2019.

11. El Hadi M. Digital revolution: digital transformation and new business models. Egyptian Journal of Information, Egyptian Society for Information Systems and Computer Technology. 2018, 21, 9-24.

12. Rakten's report. Big Data what is the importance and importance of investing in its analysis, and how will it affect our lives and decisions. https://www.urecten.com. Date accessed 14/10/2018.

13. Qashi K, Al-Awadi S. Big Data and its impact on decision making. Journal of Economics and Applied Statistics. Algeria. 2018, 14(2), 150-165. https://www.asjp.cerist.dz/en/article/32228

14. Janssen M, Voort H, Wahyudi A. Factors influencing Big Data decision-making quality. Journal of Business Research. 2017, 70, 338-345. https://doi.org/10.1016/j.jbusres.2016.08.007

15. Lotaby M. Big Data and the information industry. Al-Hikma Journal of Media and Communication Studies. University of Algiers. 2018, 6(4), 56-80. https://www.asjp.cerist.dz/en/article/72975

16. Aldridge. Big Data in portfolio allocation - a new approach to successful portfolio optimization. Journal of Financial Data Science. 2019, 1(1), 45-63. https://jfds.pm-research. com/content/1/1/45

17. Al-Akbali A. Big Data and decision making at King Saud University. Journal of Information Studies \& Technology (JIS\&T). 2019, 2018(1), 1-12. https://www.qscience.com/content/ journals/10.5339/jist.2018.15

18. Al-Shobakah Y. Awareness of the concept of Big Data for employees of academic libraries: a case study of the library of the University of Jordan. In: 24th Annual conference of the association of specialized libraries, Muscat, 6-8 March 2018; 1-28. https://library.dctabudhabi.ae/eds/detail? $\mathrm{db}=$ edshui\&an=edshui.870244\&isbn=edshui

19. Mobily Report. A vision for the future for big data analysis: opportunities and challenges. Saudi Arabia Magazine. 2018; 1-14. https://www.mobily.com.sa/portalu/wps/wcm/connect/ 6d310e25-23eb-4057-ac6c- 24b70d0c07cd/6.+Big+Data+Analytics++-+Opportunities+and+ Challenges+-+Ar.pdf?MOD=AJPERES

20. Appelbaum D, Kogan A, Vasarhely M. Analytical procedures in external auditing: a comprehensive literature survey and framework for external audit analytics. Journal of Accounting Literature. 2018, 40, 83-101. https://www.academia.edu/35884066

21. Zicari R. Big Data: challenges and opportunities. http://odbms.org. Date accessed: 05/12/2017. 
22. Cockcroft S, Russell M. Big Data opportunities for accounting and finance practice and research. CPA Journal. 2018, 28(2), 149-301. https://www.researchgate.net/publication/322938351

23. Younis N. Big Data and sustainability of higher education. Global approaches to sustainability through learning and education. 2020; 23. DOI: 10.4018/978-1-7998-0062-0.ch004. https:// www.igi-global.com/chapter/big-data-and-sustainability-of-higher-education/237438

24. Richins G, Stapleton A, Stratopoulos T, Wong C. Big Data analytics: opportunity or threat for the accounting profession. https://ssrn.com/abstract=2813817. Date accessed 15/06/2017.

25. Coyne E, Coyne J, Walker K. Big Data information governance by accountants. International Journal of Accounting and Information Management. 2018, 26 (1), 153-170. https://www. researchgate.net/publication/323024137

26. McKinney E, Yoos C, Snead K. The need for 'skeptical' accountants in the era of Big Data. Journal of Accounting Education. 2017, 38, 63-80. ciencedirect.com/science/article/abs/pii/ S0748575116301051.

27. Chua F. Big Data: its power and perils, the Big Data effect. 2016. https://www.accaglobal.com

28. Al-Htaybat K, Alberti A. Big Data and corporate reporting: impacts and paradoxes. Accounting, Auditing \& Accountability Journal. 2017, 30(4), 850-873. https://econpapers.repec.org/article/ emeaaajpp/aaaj-07-2015-2139.htm

29. Gamagea P. Big Data: are accounting educators ready. Accounting and Management Information Systems. 2016, 15(3), 588-604. https://www.coursehero.com/file/35333546

30. Sulaiman M. Supporting the ambitions of the accounting profession - the need to adapt to modern trends in information technology, the first annual conference entitled: the reality of the accounting profession between challenges and ambition. Baghdad. 16-17 April 2014; 1-22.

31. AACSB International. AACSB International Accounting Accreditation Standard A7: information technology skills and knowledge for accounting graduates: an interpretation. Tampa, Florida, September 2014. https://studylib.net/doc/10804538. Date accessed: 27/12/2019.

32. Janvrin D, Waston M. Big Data: a new twist to accounting. Journal of Accounting Education. 2017, 38, 3-8. https://www.sciencedirect.com/science/article/abs/pii/S0748575116301877

33. Warren J, Moffitt K, Byrnes P. How Big Data will change accounting. Accounting Horizons. 2015, 29 (2), 397-407. https://www.researchgate.net/publication/276391218

34. Rezaee Z, Wang J. Big Data, big impact on accounting. APLUS. 2017; 42-45. https://aplusmag. goodbarber.app/topics/c/0/i/17867251/big-data-big-impact-accounting

35. Gepp A, Linnenluecke M, O’Neill T, Smith T. Big Data techniques in auditing research and practice: current trends and future opportunities. https://ssrn.com/abstract=2930767. Date accessed: 29/12/2018. 